\title{
A hybrid of Borda and DEMTEL for productivity improvement
}

\author{
Naser Hamidi ${ }^{a^{*}}$, ParisaYousefi ${ }^{a}$, Afsaneh Rahimi ${ }^{a}$ and Fehimeh Jabari ${ }^{\mathrm{b}}$
}

${ }^{a}$ Department Of Management, Qazvin Branch, Islamic Azad university, Qazvin, Iran

${ }^{b}$ Department Of Management, Allmeh Reffiae University, Qazvin , Iran

\begin{tabular}{l}
\hline A R T I C L E I N F O \\
\hline Article history: \\
Received March 25, 2012 \\
Received in revised format \\
25 September 2012 \\
Accepted 4 October 2012 \\
Available online \\
October 72012 \\
\hline Keywords: \\
DEMATEL \\
Productivity \\
Burda
\end{tabular}
A B S T R A C T

\begin{abstract}
Human resources are believed the primary sources of building advanced technological enterprises in today's world. Improving productivity in human resources plays essential role on empowering employees. The proposed model of this paper uses a hybrid of Burda and DEMATEL to find important factors for improving manpower productivity. The proposed model of this paper uses DEMATEL technique to find cause and effect factors and propose a linear programming technique to find important factors influencing productivity improvement. The results of our survey indicate that job enrichment, service training and job enlargement and quality of work life and training embedded are among the most important factors improving manpower productivity promotion.
\end{abstract}

(c) 2012 Growing Science Ltd. All rights reserved.

\section{Introduction}

Productivity is one of the most important issues in driving business units more efficiently and there have many studies to find important factors preventing enterprises from reaching possible success. There were different studies on the obstacles of the various industries. Mooali et al. (2011) explained challenging dimensions of bureaucracy and its distraction and obstacles in the development of entrepreneurship. Amiri et al. (2010) studied the problems of entrepreneurs in Tehran and ranked them based on multi criteria decision making techniques. They categorized the problems of entrepreneurs in 7 groups including financial limitations, cultural limitations, teaching limitations, market and job places limitations, fundamental and supportive limitations, personal limitations, legal and departmental limitations. Then the researchers ranked these limitations and reported cultural issues as at the important and personal as the least important factor.

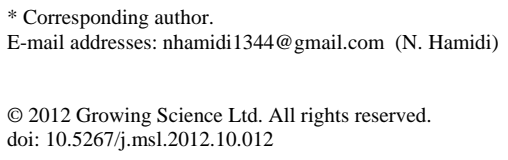


Zali and Razavi (2009) presented an empirical study on obstacles in entrepreneurship in Iran. Their statistic community was the best Iranian entrepreneurs who were selected in the festival superior national entrepreneurs in 2007. They reported 11 obstacles including financial risk, Lack of access to financial resources, Departmental obstacles, Social dangers, Illegality at departments, Lack of skill, Challenges, etc. Lamei (2007) performed an investigation on legal barriers on entrepreneurship development in Iran's small industries and determined five important factors including kind of business and work, labor law as important factors. Moqimi (2005) studied the obstacles of entrepreneurship in the industry of the country and the solution to overcome them. In this study, obstacles were categorized in three groups of behavioral, structural and field obstacles. The results of the structural obstacles revealed that the companies did not have the structure of research and development, marketing, evaluating, budgeting and informing the management.

Reducing inefficiency associated with business units is a Mutli criteria decision making (MCDM) problem. Dalalah et al. (2011), for instance, presented a hybrid fuzzy model for group MCDM where a modified fuzzy DEMATEL model was used to deal with the influential relationship between the evaluation criteria. The modified DEMATEL normally uses such relationship and divides the criteria into two groups, particularly, the cause group and the effect group. The cause group has an influence on the effect group where such influence is implemented to estimate the criteria weights. In addition, a modified TOPSIS model is proposed to make an assessment of the criteria against each alternative. They used a fuzzy distance measure in which the distance from the Fuzzy Positive Ideal Solution (FPIS) and Fuzzy Negative Ideal Solution (FNIS) are measured.

The resulted distances were implemented to measure the similarity to Ideal and Anti-ideal points. Later, they computed an optimal membership degree (closeness coefficient) of each alternative to estimate in which extent an alternative was associated with both FPIS and FNIS. Obviously, the closer the degree of membership to FPIS and the farther from FNIS the more preferred the alternative. The membership degree is achieved by the optimization of a defined objective function that locates the degree in which an alternative is similar/dissimilar to the Ideal/Anti-Ideal solutions. The closeness coefficient is implemented to rank the alternatives. To better have a high contrast between the ranks of alternatives, an optimization problem was introduced and solved to maximize the contrast. Kuoa and Liang (2011) used a novel hybrid decision-making model for selecting locations in a fuzzy environment. Tzeng et al. (2007) evaluated intertwined effects in e-learning programs in real-world case study by implementing a hybrid MCDM model based on factor analysis and DEMATEL (Fontela \& Gabus, 1976; Gabus \& Fontela, 1973; Lin \& Wu, 2008). Zhou et al. (2010, 2011) used DEMATEL technique to find barriers in inefficiency of units for different applications. Kuoa and Liang (2011) presented another MCDM technique for selecting locations in a fuzzy environment.

\section{Research method}

The proposed study of this paper uses multi attribute decision making (MADM) technique to detect important factors influencing productivity. Our survey has been performed in Qazvin and we have detected 43 factors grouped in six categories including managing, psychical-social, cultural, environmental, individual and economical. The proposed study uses a questionnaire based on Likert scale from very low (1) to very high (5).

As we can see from the figure, in the first level, there are six influencing items including management, Psychological and social, cultural, Individual, economical and environmental factors and within each group of these six factors we can find 24 influencing factors. In order to find an appropriate sample size we have used the following,

$$
n=\frac{N \times z_{\alpha / 2}^{2} \times S^{2}}{\varepsilon^{2} \times(N-1)+z_{\alpha / 2}^{2} \times S^{2}},
$$

where $N$ is the population size, $z_{\alpha / 2}$ is CDF of normal distribution and finally $\varepsilon$ is the error term. Since we have $z_{\alpha / 2}=1.96, S^{2}=90 \%, d=8 \%$ and $N=39$, the number of sample size is calculated as 
$n=23$. The proposed model of this paper uses DEMATEL technique to prioritize different factors. Fig. 1 shows details of all important factors.

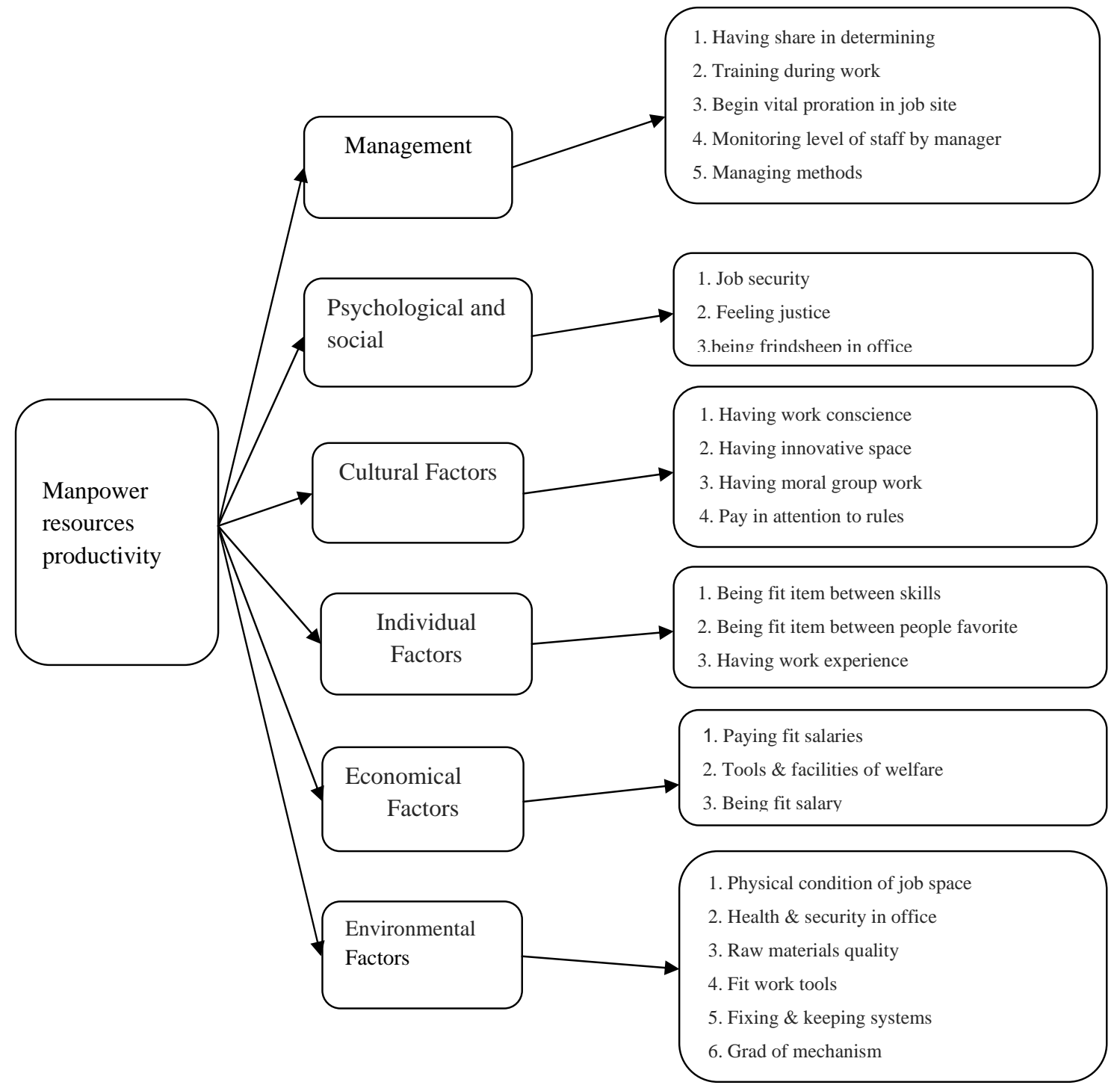

Fig. 2. The hierarchy of final standards manpower productivity tree

\section{The proposed model}

The Battelle Memorial Institute conducted a DEMATEL method project through its Geneva Research Centre (Gabus \& Fontela, 1972, 1973). The primary objective of DEMATEL was at the fragmented and antagonistic phenomena of world societies but later it became popular in many countries such as Japan since it became a comprehensive method for constructing a structural model involving causal relationships among complex factors. Digraphs are more useful than directionless graphs because digraphs can show the directed relationships of sub-systems. Moreover, the digraph portrays a basic concept of contextual relationships among the elements of the system, in which the numeral represents the strength of influence. The DEMATEL is based on digraphs, which could separate involved factors into cause and effect groups. To apply DEMATEL smoothly, this paper refines the version used by Fontela and Gabus (1976) and proposes five main steps as below. 
Step 1: Create the direct-relation matrix, First, measure the relationship between criteria where comparison scale is divided into four levels: 0 (no influence), 1 (very low influence), 2 (low influence), 3 (very high influence) and 4 (very high influence), Create sets of the pair-wise comparisons in terms of impact and direction among different criteria. As a result, the initial data can be generated as the direct-relation matrix, which is an $n \times n$ matrix $A$, in which $a_{i j}$ is denoted as the degree in which the criterion $i$ influences the criterion $j$.

Step 2: Normalize the direct-relation matrix based on the direct-relation matrix A, the normalized direct-relation matrix X can be obtained through formulas:

$$
\begin{aligned}
& X=k \cdot A \\
& k=\frac{1}{\max _{1 \leq i \leq n} \sum_{j=1}^{n} a_{i j}}, \quad i, j=1, \cdots, n
\end{aligned}
$$

Step 3: Obtain the total-relation matrix, once the normalized direct-relation matrix $\mathrm{X}$ is calculated, the total relation matrix $\mathrm{T}$ can be acquired by using Eq. (3), in which the I is identity matrix

$$
T=X(I-X)^{-1}
$$

Step 5: Set a threshold value and obtain the network relationship map (NRM), To explain the structural relationship among the criteria and keep the complexity of the system to a manageable level at the same time, it is necessary to set a threshold value $p$ to filter out some negligible effects in matrix T. Only some criteria, whose effect in matrix $\mathrm{T}$ is greater than the threshold value, should be chosen and shown in a network relationship map (NRM) for influence (Tzeng et al., 2007). In this paper, experts decided the threshold value is arithmetic mean of $T$ matrix numbers. After the threshold value is decided, the final influence result of criteria can be calculated.

\subsection{Data analysis}

The findings resulted from step by step methodology implementation is presented as following. This research used 10 experts of SAPCO Company.

C1: Management, C2: Culture, C3: Psychological and social, C4: Cultural, C5: Individual, C6: Economical and environmental.

Table 1

Direct relationship Matrix

\begin{tabular}{ccccccc}
\hline \multicolumn{1}{c}{ C1 } & C2 & C3 & C4 & C5 & C6 \\
\hline C1 & 0.0101 & 0.1361 & 0.202 & 0.2494 & 0.6356 & 0.1010 \\
& & & 0 & & & \\
C2 & 0 & 0.2041 & 0 & 0.2041 & 0.3878 & 0 \\
C3 & 0 & 0 & 0 & 0 & 0.3000 & 0 \\
C4 & 0 & 0.1020 & 0 & 0.2041 & 0.4388 & 0 \\
C5 & 0 & 0 & 0 & 0 & 0 & 0 \\
C6 & 0.101 & 0.1361 & 0.202 & 0.2494 & 0.4901 & 0.0101 \\
\hline
\end{tabular}

Table 2

Inner Dependence matrix

\begin{tabular}{ccccccc}
\hline & C1 & C2 & C3 & C4 & C5 & C6 \\
\hline C1 & 0.010 & 0.036 & 0.002 & 0.049 & 0.236 & 0.001 \\
& & & & & & \\
C2 & 0 & 0.2041 & 0 & 0.004 & 0.088 & 0 \\
C3 & 0 & 0 & 0 & 0 & 0 & 0 \\
C4 & 0 & 0.002 & 0 & 0.204 & 0.438 & 0 \\
C5 & 0 & 1.320 & 1.243 & 0 & 0 & 0 \\
C6 & 0.001 & 0.036 & 0.202 & 0.049 & 0.190 & 0.010 \\
\hline
\end{tabular}

We allocate code 1,2,3,4,5,6 grades for stating vocal context management, economical, cultural, psychical-social, environmental, individual . Fig. 3 shows the relationships between different factors.

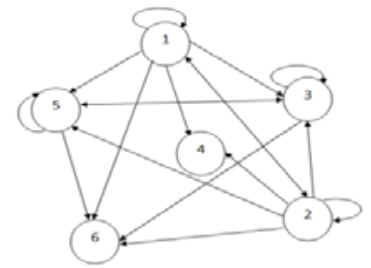

Fig. 3. Indirect relations with existing ratio intensity 
Table 3

The order of different criteria based on various perspectives

\begin{tabular}{|c|c|c|c|c|c|c|c|}
\hline Criteria order & $\begin{array}{l}\text { On the basis } \\
\text { of } \mathrm{R}\end{array}$ & Criteria order & $\begin{array}{c}\text { On the basis } \\
\text { of } \mathrm{D}\end{array}$ & Criteria order & $\begin{array}{l}\text { On the } \\
\text { basis of } \\
(\mathrm{R}+\mathrm{D})\end{array}$ & Criteria order & $\begin{array}{c}\text { On the basis } \\
\text { of (R-D) }\end{array}$ \\
\hline Managing & 1.324157 & individual & 2.252155 & individual & 2.252155 & Managing & 1.313955 \\
\hline Economical & 1.006885 & environmental & 0.723356 & Managing & 1.354359 & Economical & 0.895774 \\
\hline Cultural & 0.612245 & cultural & 0.394557 & Environmental & 1.284581 & Cultural & 0.217688 \\
\hline Environmental & 0.561225 & psychical-social & 0.222222 & economical & 1.117996 & psychical-social & 0.077778 \\
\hline psychical-social & 0.3 & economical & 0.111111 & cultural & 1.006802 & environmental & -0.162131 \\
\hline individual & 0 & Managing & 0.020202 & psychical-social & 0.522222 & Individual & -2.252155 \\
\hline
\end{tabular}

The hierarchy of final of direct relation and nondirective of factors, instead of stated problem with attention to $(\mathrm{R}+\mathrm{D})$ and $(\mathrm{R}-\mathrm{D})$ worthies are as follows,

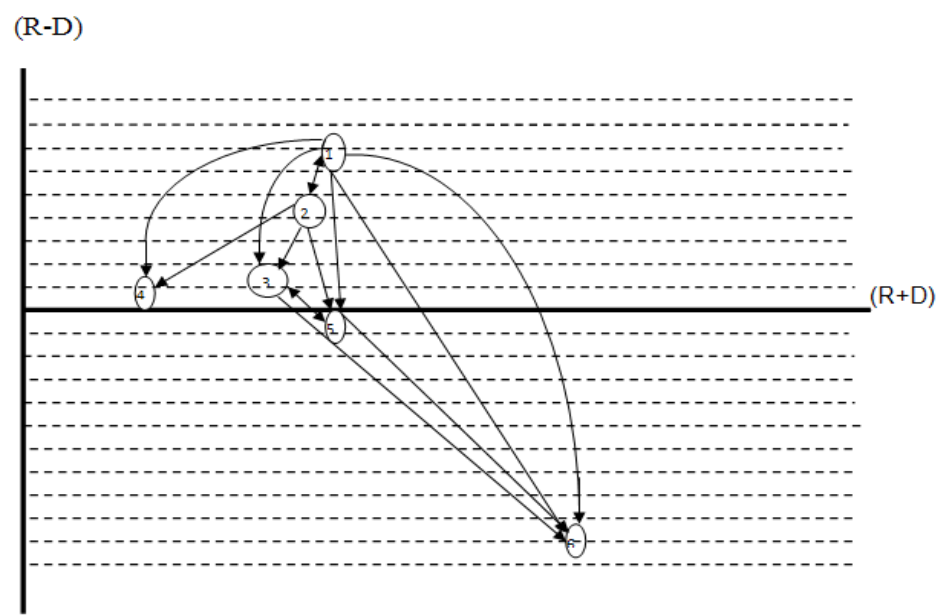

The hierarchy of final of direct relation and nondirective of factors

Once the results of the implementation of DEMATEL becomes clear, we ask some experts to allocate their ranking one more time and the results of their insights are summarized in Table 4.

Table 4

The results of voting before and after ranking

\begin{tabular}{lcccccc}
\hline & Management & Culture & Psychological and social & Environmental & Individual & Economical \\
\hline Management & 1 & 3 & 4 & 4 & 2 & 6 \\
Culture & $1 / 3$ & 1 & 3 & 2 & 5 & $1 / 3$ \\
Psychological and social & $1 / 4$ & $1 / 3$ & 1 & 1 & 4 & 3 \\
Environmental & $1 / 4$ & $1 / 2$ & $1 / 2$ & $1 / 3$ & 1 & $1 / 3$ \\
Individual & $1 / 5$ & $1 / 5$ & $1 / 4$ & 4 & 5 & $1 / 5$ \\
Economical & 4 & 4 & 5 & & 2 & 1 \\
\hline
\end{tabular}

Now, we repeat the process one more time and the results of our ranking before and after the experts visited the results are summarized in Table 5 as follows,

\section{Table 5}

The summary of ranking before and after the implementation of the proposed model

\begin{tabular}{lcccccc}
\hline & Management & Culture & Psychological and social & Environmental & Individual & Economical \\
\hline Before & 0.354314 & 0.095013 & 0.108162 & 0.222579 & 0.111049 & 0.108883 \\
After & 0.115571 & 0.256489 & 0.193593 & 0.137092 & 0.057910 & 0.239345 \\
\hline
\end{tabular}

There are five plans to increase the productivity, which are in service training, training embedded with work, job enrichment, job enlargement and quality of work life and the weights assigned to these five components before and after visiting the results of Table 6 are summarized as follows, 


\section{Table 6}

The weights of the productivity improvement

\begin{tabular}{lccccc}
\hline Program & \multicolumn{2}{c}{ Rank } \\
\hline & One & Two & Three & Four & Five \\
\hline In service training & 0.288206 & 0.399736 & 0.10816 & 0.203896 & 0 \\
Training embedded with work & 0 & 0.0555245 & 0.0555245 & 0.354314 & 0.534637 \\
Job enrichment & 0.507898 & 0.0555245 & 0.0555245 & 0 & 0 \\
Job enlargement & 0 & 0 & 0.426475 & 0.219211 & 0.354314 \\
Quality of work life & 0.203896 & 0.108162 & 0.354314 & 0.222579 & 0.111049 \\
\hline
\end{tabular}

Let $h_{i j}$ be a binary variable. Based on the results of Table 6 , we build the following mixed integer programming to find the best combination of work.

$$
\begin{aligned}
& \max \quad 0.288206 \mathrm{~h}_{1,1}+0.399736 \mathrm{~h}_{1,2}{ }^{+} \quad 0.108162 \mathrm{~h}_{1,3}+0.203896 \mathrm{~h}_{1,4}+0.0555245 \mathrm{~h}_{2,2}+0.0555245 \mathrm{~h}_{2,3}{ }^{+} \\
& 0.354314 \mathrm{~h}_{2,4}+0.534637 \quad \mathrm{~h}_{2,5+} 0.507898 \quad \mathrm{~h}_{3,1}+0.4365775 \mathrm{~h}_{3,2}+0.0555245 \mathrm{~h}_{3,3} \quad+0.426475 \mathrm{~h}_{4,3}+0.219211 \mathrm{~h}_{4,4}+ \\
& 0.354314 \mathrm{~h}_{4,5}+0.111049 \mathrm{~h}_{5,1}+0.222579 \mathrm{~h}_{5,2}+0.354314 \mathrm{~h}_{5,3}+0.108162 \mathrm{~h}_{5,4}+0.203896 \mathrm{~h}_{5,5}
\end{aligned}
$$

$$
\begin{aligned}
& \text { subject to } \quad \mathrm{h}_{1,1}+\mathrm{h}_{2,1}+\mathrm{h}_{3,1}+\mathrm{h}_{4,1}+\mathrm{h}_{5,1}=1 \\
& \mathrm{~h}_{1,1}+\mathrm{h}_{1,2}+\mathrm{h}_{1,3}+\mathrm{h}_{1,4}+\mathrm{h}_{1,5}=1 \\
& \mathrm{~h}_{1,2}+\mathrm{h}_{2,2}+\mathrm{h}_{3,2}+\mathrm{h}_{4,2}+\mathrm{h}_{5,2}=1 \\
& \mathrm{~h}_{2,1}+\mathrm{h}_{2,2}+\mathrm{h}_{2,3}+\mathrm{h}_{2,4}+\mathrm{h}_{2,5}=1 \\
& \mathrm{~h}_{1,3}+\mathrm{h}_{2,3}+\mathrm{h}_{3,3}+\mathrm{h}_{4,3}+\mathrm{h}_{5,3}=1 \\
& \mathrm{~h}_{3,1}+\mathrm{h}_{3,2}+\mathrm{h}_{3,3}+\mathrm{h}_{3,4}+\mathrm{h}_{3,5}=1 \\
& \mathrm{~h}_{1,4}+\mathrm{h}_{2,4}+\mathrm{h}_{3,4}+\mathrm{h}_{4,4}+\mathrm{h}_{5,4}=1 \\
& \mathrm{~h}_{4,1}+\mathrm{h}_{4,2}+\mathrm{h}_{4,3}+\mathrm{h}_{4,4}+\mathrm{h}_{4,5}=1 \\
& \mathrm{~h}_{1,5}+\mathrm{h}_{2,5}+\mathrm{h}_{3,5}+\mathrm{h}_{4,5}+\mathrm{h}_{5,5}=1 \\
& \mathrm{~h}_{5,1}+\mathrm{h}_{5,2}+\mathrm{h}_{5,3}+\mathrm{h}_{5,4}+\mathrm{h}_{5,5}=1
\end{aligned}
$$

We repeat ranking process for different programs after experts see the results of DEMATEL and Table 7 summarizes the results.

\section{Table 7}

The weights of the productivity improvement

\begin{tabular}{lccccc}
\hline Program & \multicolumn{2}{c}{ Rank } & four & Five \\
\hline & one & two & three & 0.495834 & 0 \\
in service training & 0.1156955 & 0.1948775 & 0.193593 & 0.115571 & 0.826519 \\
$\quad$ training embedded with work & 0 & 0.028955 & 0.028955 & 0 & 0 \\
job enrichment & 0.3884705 & 0.582545 & 0.028955 & 0.251503 & 0.115571 \\
job enlargement & 0 & 0 & 0.632926 & 0.137092 & 0.057910 \\
quality of work life & 0.495834 & 0.193593 & 0.115571 & & \\
\hline
\end{tabular}

Again, based on the information we build the same mathematical model,

$$
\begin{aligned}
& \max : 0.1156955 \mathrm{~h}_{1,1}+0.1948775 \mathrm{~h}_{1,2}+0.193593 \mathrm{~h}_{1,3}+0.495834 \mathrm{~h}_{1,4}+0.028955 \mathrm{~h}_{2,2}+0.028955 \mathrm{~h}_{2,3}+ \\
& 0115571 \mathrm{~h}_{2,4}+0826519 \mathrm{~h}_{2,5}+0.3884705 \mathrm{~h}_{3,1}+0.5825745 \mathrm{~h}_{3,2}+0.028955 \mathrm{~h}_{3,3} \\
& +0.632926 \mathrm{~h}_{4,3}+0.251503 \mathrm{~h}_{4,4}+0.115571 \mathrm{~h}_{4,5}+0.495834 \mathrm{~h}_{5,1} 0.193593 \mathrm{~h}_{5,2}+0.115571 \mathrm{~h}_{5,3} 0.137092 \mathrm{~h}_{5,4}+0.05791 \mathrm{~h}_{5,5} \\
& \text { subject to } \quad \mathrm{h}_{1,1}+\mathrm{h}_{2,1}+\mathrm{h}_{3,1}+\mathrm{h}_{4,1}+\mathrm{h}_{5,1}=1 \\
& \mathrm{~h}_{1,1}+\mathrm{h}_{1,2}+\mathrm{h}_{1,3}+\mathrm{h}_{1,4}+\mathrm{h}_{1,5}=1 \\
& \mathrm{~h}_{1,2}+\mathrm{h}_{2,2}+\mathrm{h}_{3,2}+\mathrm{h}_{4,2}+\mathrm{h}_{5,2}=1 \\
& \mathrm{~h}_{2,1}+\mathrm{h}_{2,2}+\mathrm{h}_{2,3}+\mathrm{h}_{2,4}+\mathrm{h}_{2,5}=1 \\
& \mathrm{~h}_{1,3}+\mathrm{h}_{2,3}+\mathrm{h}_{3,3}+\mathrm{h}_{4,3}+\mathrm{h}_{5,3}=1 \\
& \mathrm{~h}_{3,1}+\mathrm{h}_{3,2}+\mathrm{h}_{3,3}+\mathrm{h}_{3,4}+\mathrm{h}_{3,5}=1 \\
& \mathrm{~h}_{1,4}+\mathrm{h}_{2,4}+\mathrm{h}_{3,4}+\mathrm{h}_{4,4}+\mathrm{h}_{5,4}=1 \\
& \mathrm{~h}_{4,1}+\mathrm{h}_{4,2}+\mathrm{h}_{4,3}+\mathrm{h}_{4,4}+\mathrm{h}_{4,5}=1 \\
& \mathrm{~h}_{1,5}+\mathrm{h}_{2,5}+\mathrm{h}_{3,5}+\mathrm{h}_{4,5}+\mathrm{h}_{5,5}=1 \\
& h_{5,1}+h_{5,2}+h_{5,3}+h_{5,4}+h_{5,5}=1
\end{aligned}
$$


The results of solving two mathematical models are summarized in Table 8 as follows,

\section{Table 8}

The results of ranking before and after our experts visit DEMATEL results

\begin{tabular}{cccc}
\hline Row & Before experts visits the results of DEMATEL & After experts visits the results of DEMATEL & Row \\
\hline 1 & job enrichment & quality of work life & 1 \\
2 & in service training & job enrichment & 2 \\
3 & job enlargement & job enlargement & 3 \\
4 & quality of work life & in service training & 4 \\
5 & training embedded with work & training embedded with work & 5 \\
\hline
\end{tabular}

As we can observe from the results of Table 8, job enrichment was the first priority followed by in service training and job enlargement and quality of work life and training embedded with work come in the last priorities. However, after we asked our experts to see the results of the implementation of DEMTEL we realize that quality of work life comes first in priority and job enrichment, which was first before now comes in the second position.

\section{Conclusion}

Human resources management is one of the most important factors in building better organizations. Having more skilled human resources are the primary sources of building advanced technological enterprises in today's world. Improving productivity in human resources plays essential role on empowering employees. In this paper, we have presented a hybrid method based on two methods of Burda and DEMATEL to find important factors for improving productivity of human resources. The proposed model of this paper has implemented DEMATEL technique to find cause and effect factors and proposed a linear programming technique to find important factors influencing productivity improvement. The results of our survey indicate that job enrichment, service training and job enlargement and quality of work life and training embedded are among the most important factors improving manpower productivity promotion.

\section{Acknowledgment}

The authors would like to thank the anonymous referees for constructive comments on earlier version of this paper.

\section{References}

Amiri,M., Zali,M., \& Majd,M. (2010). The limitation of launching new business. Journal of Entrepreneurship Development, 3, 81-102.

Dalalah, D., Hayajneh, M., \& Batieha, F. (2011). A fuzzy multi-criteria decision making model for supplier selection. Expert Systems with Applications, 38, 8384-8391.

Fontela, E., \& Gabus, A. (1976). The DEMATEL observer. DEMATEL 1976 Report. Switzerland, Geneva: Battelle Geneva Research Center.

Gabus, A., \& Fontela, E. (1973). Perceptions of the world problematique: communication procedure, communicating with those bearing collective responsibility. DEMATEL Report No. 1. Geneva, Switzerland: Battelle Geneva Research Center.

Gunday,G.,Ulusoy, G., \& Kilic,K. (2011). Effects of innovation types on firm performance. International Journal of Production Economics, 133, 662-676.

Hisrich, R. D., Peters, M. P. \& Shepherd Dean, A. (2005). Entrepreneurship. $6^{\text {th }}$ ed., Boston, MC Graw Hill.

Huang, H. C. (2009). Designing a knowledge-based system for strategic planning: A balanced scorecard perspective. Expert Systems with Applications, 36(1), 209-218.

Kuoa, M.S., \& Liang, G.S. (2011). A novel hybrid decision-making model for selecting locations in a fuzzy environment. Mathematical and Computer Modelling, 54, 88-104. 
Lamei, B. (2007). Legal obstacles of entrepreneurship Development in Iran's small industry. Entrepreneurship Development Center in Iran.

Lee, Y. C., Lee, M. L., Yen, T. M., \& Huang, T. H. (2011). Analysis of fuzzy Decision Making Trial and Evaluation Laboratory on technology acceptance model. Expert Systems with Applications, 38(12), 1440714416.

Lin, C. J., \& Wu, W. W. (2008). A causal analytical method for group decision-making under fuzzy environment. Expert Systems with Applications, 34(1), 205-213.

Mooali. A., Mohamadi, F., \& Saedi kia, M.(2011). Entrepreneurship is as an answer to inert of the bureaucracy in creating job opportunities. $1^{\text {st }}$ International Conference on Management, Innovation and Entrepreneurship ( $16^{\text {th }}$ and $17^{\text {th }}$ February-Shiraz, Iran).

Opricovic, S., Tzeng, G.H. (2003). Defuzzification within a multicriteria decision model. International Journal of Uncertainty, Fuzziness and Knowledge-based Systems, 11, 635-652.

Tzeng, G. H., Chiang, C. H., \& Li, C. W. (2007). Evaluating intertwined effects in elearning programs: A novel hybrid MCDM model based on factor analysis and DEMATEL. Expert Systems with Applications, 32, 1028-1044.

Zhou, Q., Huang, W., \& Zhang Y. (2010). Identifying success factors in emergency management using a fuzzy DEMATEL method . Safety Science, 49(2), 243-252.

Zhou,Q., Huang, W., \& Zhang,Y. (2011). Identifying critical success factors in emergency management using a fuzzy DEMATEL method. Expert Systems with Applications, 49, 243-259. 